\title{
PHYSICAL MODELLING OF THE RESPONSE OF NON-NOURISHED AND NOURISHED BEACH PROFILES TO STORM SURGE OR SEA LEVEL RISE
}

\author{
Alexander Atkinson, University of Queensland, a.atkinson1@uq.edu.au \\ Tom Baldock, University of Queensland, t.baldock@uq.edu.au
}

\section{INTRODUCTION}

Beach nourishment is a key strategy used to mitigate against the effects beach erosion under storm surge or sea level rise (SLR). Comparisons of different strategies are very difficult under field conditions. This paper presents the results of medium scale experiments that investigate the response of non-nourished and nourished beach profiles to water level rise, using three different nourishment strategies. The shoreline recession and profile response are compared to predictions from the Bruun rule (Bruun, 1962), recent modifications (Rosati et al., 2013) and a profile translation model that conserves the shape of the initial profile and the sediment volume.

\section{EXPERIMENTAL SETUP}

Beach profile evolution was measured for medium scale experiments in a wave flume $(20 \mathrm{~m}$ long, $1 \mathrm{~m}$ wide, $0.6 \mathrm{~m}$ water depth) with active wave absorption. Random waves $\left(\mathrm{H}_{\mathrm{m} 0}=0.13 \mathrm{~m}, \mathrm{~T}_{\mathrm{p}}=1.2 \mathrm{~s}\right)$ were used for the barred profile experiment and regular waves for the bermed profile experiment $(H=0.07 m, T=2 s)$. The sediment grain size was $d_{50}=0.3 \mathrm{~mm}$. The same wave conditions were used for pairs of non-nourished-nourished beaches, commencing from plane and power-law beach profiles. Bathymetry was measured at high spatial and temporal resolution using a combined sub-aerial and sub-aqueous laser profiler that provides 8 simultaneous profiles across the width of the flume (Atkinson and Baldock, 2018. All tests were run to near-equilibrium conditions, i.e. no significant change in bathymetry or shoreline position. Further general information is given in Atkinson et al. (2018). After formation of an equilibrium profile at the initial water level $(z=0)$, the beach was nourished with one of three different placement strategies (figure 1), the water level was raised (by approximately $\mathrm{H}_{\mathrm{m} 0} / 2$ ) and the same waves were repeated, again until the profile stabilised. The nourishment volume was designed to offset sediment demand predicted by the models noted above and correspond to an outer surf zone placement, an inner surf and upper beach placement and nourishment landward of a naturally formed beach berm.

The original Bruun Rule was assessed to compare its prediction with the observed shoreline and mean profile recession. Rosati et al.'s (2013) modified Bruun Rule (R13n, Table 1) was also tested, with an additional term (Following Stive et al., 1991) which incorporates the nourishment volume, $V_{N}$, as an additional term:

$$
R=S L R \frac{W+\frac{\left[V_{D}-V_{N}\right]}{S L R}}{B+h_{*}}
$$

where $W$ is the horizontal distance between the berm crest (at height $B$ above the still water level) and the offshore limit, at depth, $h_{*}$, and $V_{D}$ is Rosati et al.'s deposition volume.

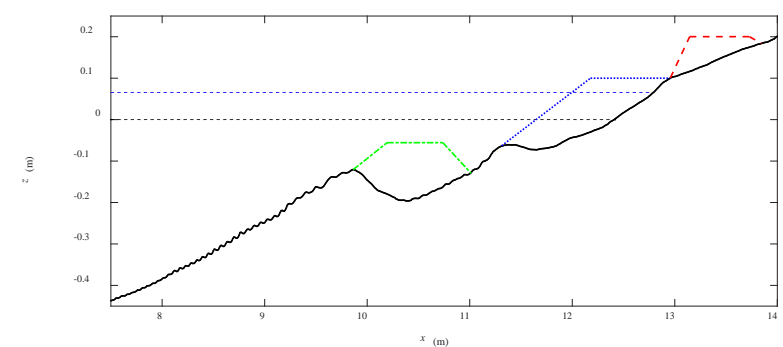

Figure 1 - Conceptual sketch of different nourishment placements (green, blue, red) on an equilibrium beach profile (black solid) formed at water level $z=0$ (black dashed) and raised level (blue dashed line).

\section{RESULTS}

Table 1 summarises the results of the experiments with shoreline $\left(R_{\text {shore}}\right)$ and mean profile recession $(R m)$, as well as the predicted recession of the three models assessed. Two classical beach profiles formed for erosive and accretionary wave conditions at the initial water level, a double longshore bar and trough system, with erosion of the upper beach (figure 2, blue lines), and a berm profile formed by onshore sediment transport (figure 3), respectively.

Table 1 - Results overview of nourishment experiments, with the water level change (SLR), shoreline recession $\left(R_{\text {shore }}\right)$, mean profile recession $\left(R_{m}\right)$, and the predictions of the three models (Bruun, R13n, and PTM).

\begin{tabular}{|c|c|c|c|c|ccc|c|}
\cline { 5 - 9 } \multicolumn{1}{c|}{} & Bruun & \multicolumn{3}{|c|}{ R13n } & PTM \\
\hline ID & SLR & $\boldsymbol{R}_{\text {shore }}$ & $\boldsymbol{R}_{\boldsymbol{m}}$ & $R$ & $V D$ & $V N$ & $R$ & $R$ \\
\hline A2 & {$[\mathrm{m}]$} & {$[\mathrm{m}]$} & {$[\mathrm{m}]$} & {$[\mathrm{m}]$} & {$\left[\mathrm{m}^{3} / \mathrm{m}\right]$} & {$\left[\mathrm{m}^{3} / \mathrm{m}\right]$} & {$[\mathrm{m}]$} & {$[\mathrm{m}]$} \\
\hline NA1 & 0.035 & 0.312 & 0.328 & 0.291 & 0.032 & - & 0.342 & 0.358 \\
E2 & 0.035 & 0.140 & 0.300 & 0.289 & - & 0.030 & 0.237 & 0.240 \\
NE2 & 0.065 & 0.883 & 0.698 & 0.665 & 0.001 & - & 0.666 & 0.663 \\
\hline
\end{tabular}

The final equilibrium profile for the non-nourished barred profile after water level rise (figure $2 a$, black line) shows strong erosion of the upper beach, with translation of both bars shoreward. The shoreline recession $\left(R_{\text {shore }}=\right.$ $0.88 \mathrm{~m}$ ) is under-predicted by the Bruun rule $(R=0.67$ $\mathrm{m})$. The post-water level rise profile for the nourished profile (figure 2b, black line) shows much less nearshore erosion and a $30 \%$ reduction in shoreline recession than the non-nourished profile (figure 2a, black line), with the outer bar further inshore. 
The final equilibrium profile for the non-nourished bermed profile after water level rise (figure 3a, black line) shows erosion of the upper beach with landward migration of the berm, through overtopping. The shoreline recession $\left(R_{\text {shore }}=0.31 \mathrm{~m}\right)$ is closely predicted by the Bruun rule $(R=0.29 \mathrm{~m})$. The nourishment volume (figure $3 \mathrm{~b}$, red line) was designed to prevent the berm overtopping, which increases the recession (Rosati et al., 2013) Following the water level rise, the nourished profile (figure $2 b$, black line) continued to accrete, substantially reducing the shoreline recession $\left(R_{\text {shore }}=0.18 \mathrm{~m}\right.$ ) by approximately $40 \%$.
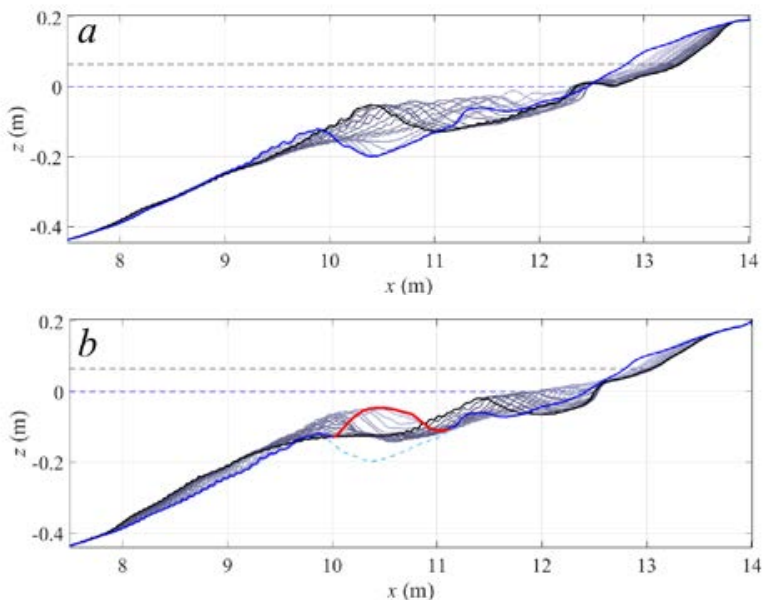

Figure 2 - Non-nourished (a) and nourished (b) profile development at raised water level. Nourishment is indicated as the red line in (b). Profile development progresses from blue, through darkening greys to black, final profile after 50 hours of waves at water level $z=0.065 \mathrm{~m}$.

The profile shift and observed recession are in better agreement with the Bruun rule after accounting for the nourishment volume as achieved by the R13n model and the PTM (Table 1). A comparison of the shoreline recession and mean recession of the profile for nonnourished and nourished beaches is shown in Figure 4. In every instance, the nourishment resulted in a reduced recession. The shoreline recession was reduced to a greater extent than the mean recession in all cases.

\section{CONCLUSIONS}

Beach evolution under storm surge or SLR conditions has been investigated for three different beach nourishment strategies, and compared to non-nourished conditions. In every instance, the recession (both shoreline and mean profile) was reduced in the nourishment scenario. Quantitative comparisons were made between the observed shoreline and mean profile recession with the predictions for the Bruun rule (Bruun, 1962), Rosati et al.'s (2013) modification that incorporates the nourishment volume and profile translation model. The results indicate that including the nourishment volume in the calculation provides more accurate recession predictions.
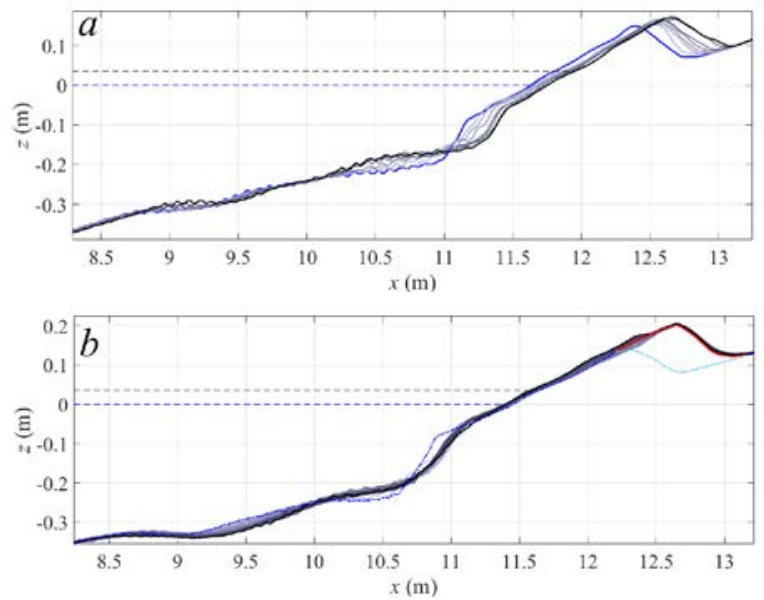

Figure 3 - Non-nourished (a) and nourished (b) profile development at raised water level. Nourishment is indicated as the red line in (b). Profile development progresses from blue, through darkening greys to black, final profile after 12 hours of waves at water level $z=0.035 \mathrm{~m}$.



Figure 4 - Comparison of nourished (NA1, NE1, NE2, and NE3) versus non-nourished (A2, E2, and E3) shoreline and mean-profile recession. Legend: Rshore blue diamonds; $R_{m}$ - red squares.

\section{REFERENCES}

Atkinson and Baldock (2016): A high-resolution subaerial and sub-aqueous laser based laboratory beach profile measurement system. Coastal Engineering, 107, 28-33.

Atkinson, Baldock, Birrien, Callaghan, Nielsen, Beuzen, Turner, Blenkinsopp and Ranasinghe (2018): Laboratory investigation of the Bruun Rule and beach response to sea level rise. Coastal Engineering. 136, pp. 183-202.

Bruun (1962). Sea-level rise as a cause of shore erosion. Journal of the Waterways and Harbors division, 88(1), 117-132.

Rosati et al., (2013): The Modified Bruun Rule Extended for Landward Transport. Marine Geology, 340, 71-81.

Stive, Nicholls and de Vriend (1991): Sea-level rise and shore nourishment: a discussion. Coastal Engineering, 16(1), pp.147-163. 